\title{
Hospital room or treatment room for pediatric inpatient procedures: which location do parents and children prefer?
}

\author{
Debra Fanurik $\mathrm{PhD}^{1,2}$, Michael L Schmitz $\mathrm{MD}^{1,2}$, Kelle Reach BA ${ }^{1}$, Katherine Haynes BA ${ }^{1}$, Isabel Leatherman $\mathrm{BA}^{1}$
}

D Fanurik, ML Schmitz, K Reach, K Haynes, I Leatherman. Hospital room or treatment room for pediatric inpatient procedures: which location do parents and children prefer? Pain Res Manage 2000;4(2):148-156.

OBJECTIVE: The acute pain management guidelines put forth by the Agency for Health Care Policy and Research recommend that inpatient pediatric procedures be performed in a treatment room rather than in a child's hospital room. However, hospitals vary widely in their use of treatment rooms for pediatric procedures. Because there has been little empirical investigation of this clinical issue, the present study explores the preferences of parents and children regarding the performance site of inpatient procedures.

SUBJECTS AND METHODS: One hundred and sixty parents of hospitalized children three to 14 years of age were interviewed about previous experience with medical procedures, procedure site preference (treatment room or hospital room) and reasons for room preference. Children five years of age and older were also asked for their preferences regarding the procedure site.

RESULTS: The hospital room was preferred by the majority of parents and children for minor procedures (blood test, intravenous insertion, bandage change) for reasons consisting primarily of the child's emotional or physical comfort, convenience and difficulties moving the child due to motor impairment or medical condition. The treatment room was generally selected for more invasive procedures (lumbar punctures, bone marrow aspirations, bladder catheterizations) due to concerns for the privacy of the child and roommate, and the need for special equipment or supplies.

CONCLUSIONS: Results suggest that parents and children may prefer the hospital room or treatment room for a variety of different reasons. More research is needed in this area to develop better guidelines regarding the performance of inpatient pediatric procedures.

Key Words: Acute pain; Children; Medical procedures; Treatment room

\section{Chambre d'hôpital ou salle de traitement pour les interventions chez les enfants hospitalisés : préférence des parents et des enfants}

OBJECTIF : Selon les recommandations de l'Agency for Health Care Policy and Research en ce qui concerne le traitement de la douleur aiguë, les interventions chez les enfants hospitalisés devraient se pratiquer dans les salles de traitement plutôt que dans la chambre d'hôpital. Cependant, l'utilisation des salles de traitement pour ce genre d'intervention varie beaucoup entre les hôpitaux. Comme peu de recherches empiriques ont été menées sur le sujet, la présente étude porte sur la préférence des parents et des enfants quant au lieu où devraient se faire les interventions chez les enfants hospitalisés.

SUJETS ET MÉTHODE : Cent soixante parents d'enfants hospitalisés, âgés de trois à quatorze ans, ont été interrogés sur leur expérience passée concernant différentes interventions médicales, leur préférence quant au lieu des interventions (chambre d'hôpital ou salle de traitement) et les raisons pour lesquelles ils préfèrent la chambre d'hôpital. On a également demandé aux enfants âgés de cinq ans et plus leur préférence quant au lieu des interventions.

RÉSULTATS : La majorité des parents et des enfants ont exprimé une

voir page suivante

\footnotetext{
${ }^{1}$ Department of Anesthesia, ${ }^{2}$ Department of Pediatrics, University of Arkansas for Medical Sciences, Arkansas Children's Hospital, Little Rock, Arkansas, USA Correspondence and reprints: Dr Debra Fanurik, Arkansas Children's Hospital, Division of Pediatric Anesthesia, 800 Marshall Street, SLOT 203,

Little Rock, Arkansas 72202, USA. Telephone 501-320-6575, fax 501-320-2939, e-mail FanurikDebra@exchange.uams.edu
} 
préférence pour la chambre d'hôpital pour les petites interventions (prélèvement sanguin, installation intraveineuse, changement de pansements) surtout pour des raisons pratiques, de confort physique et émotionnel et de contraintes de déplacement attribuables à des difficultés motrices ou à la maladie. La salle de traitement a été généralement choisie pour les interventions plus effractives (ponction lombaire, aspiration de la moelle osseuse, cathétérisme vésical) pour des questions d'intimité et de respect des autres enfants dans la chambre ainsi que d'utilisation de matériel ou d'équipement particuliers. CONCLUSIONS : Les résultats révèlent que les parents et les enfants peuvent préférer la chambre d'hôpital ou la salle de traitement pour une foule de raisons. Il faudrait faire plus de recherche dans le domaine pour élaborer de meilleures lignes de conduite concernant les interventions pratiquées chez les enfants hospitalisés.
$I^{n}$ nvasive medical procedures are a significant source of distress for both children and parents. There have been numerous investigations documenting the effectiveness of pharmacological and behavioural interventions in reducing the pain and anxiety associated with pediatric procedures; however, virtually all of this research has been conducted in the outpatient setting (1-6). Children's ability to cope with inpatient medical procedures has received little empirical study, although invasive procedures are frequent occurrences for hospitalized children. One primary focus of attention is the location of inpatient procedures. The current clinical practice guidelines on acute pain in children recommend that medical procedures not be performed in the child's hospital bed or room (7). The reasoning behind this recommendation is clearly to keep the hospital room a 'safe' place where the child does not have to worry that something painful will be done to them.

Nursing textbooks have incorporated these guidelines, suggesting that procedures be performed in a treatment room in order to keep the child's hospital room, as well as the hospital play room, safe from painful occurrences (8-11). Pediatric pain experts also recommend the use of treatment rooms $(12,13)$. However, there are few empirical data supporting the rationale for the guidelines. In addition, there is little discussion of the practical aspects of removing the child from the hospital room or specific guidelines about making decisions for individual children.

Schechter et al (14) described the infrequent use of treatment rooms in their pediatric hospital as well as the exclusion of parents when the treatment rooms were used. Despite the implementation of a structured clinical program targeting better pain management practices, the authors noted that the treatment room continued to be underused. Indeed, clinical experience suggests that the use of treatment rooms varies widely across pediatric hospitals. Given the guidelines and concerns about the sanctity of the child's hospital room, it seems puzzling that treatment rooms continue to be infrequently used for inpatient procedures.

A recent investigation with inpatient pediatric nurses offers some insight as to why treatment rooms are underused (15). In this study, nurses were presented with vignettes that systematically manipulated the age of the child and invasiveness of the procedure. Nurses were asked to select a site for performing the procedure (either hospital room or procedure room). The hospital room was more likely to be selected for a less invasive procedure and for an older child. In addition to age and type of procedure, nurses identified a number of other factors that they felt were important to the issue of procedure location. These factors included the child's coping ability, child's health condition, need for special equipment or sterile conditions, and type of hospital room (private, semiprivate or intensive care room). Surprisingly, only $4 \%$ of the nurses stated that asking the child and/or parent for their opinion regarding room choice was an important consideration.

There is growing attention to parents' participation during their children's medical procedures (16-20), and it seems beneficial to obtain parental input about where to perform their children's procedures as well. Indeed, the acute pain guidelines (7) call for parent education and input regarding their children's acute pain management. In an effort to obtain parental input on this clinical issue, parents of hospitalized children (and children five years of age and older) were interviewed about their preference for performance site of inpatient procedures. Data were also gathered to examine potential relationships between preference for procedure location and factors such as the child's age, extent of previous experience and medical condition.

\section{Participants and setting}

\section{SUBJECTS AND METHODS}

Participants were parents of 160 children, aged three to 14 years (75 females, 85 males), who were inpatients at a regional children's hospital. Children five years of age and older also participated. This study was approved by the $\mathrm{Hu}-$ man Research Advisory Committee of the hospital and the medical school with which the hospital is affiliated. Eligibility criteria included having experienced at least one inpatient medical procedure. Recruitment was balanced by age of child (three to five years, six to eight years, nine to 11 years and 12 to 14 years, with 40,37, 42 and 41 children in each age group, respectively) and inpatient ward (hematology/oncology, neurology/rehabilitation, surgery and medicine). These inpatient wards comprise two hospital floors, and a treatment room is located on each floor. There is no written hospital policy on the use of the treatment room for inpatient procedures.

\section{Procedures}

Before the study commenced, four research assistants underwent training to standardize the recruitment and interview procedures. Parents of children within the targeted age range were approached in their hospital room to explain the study procedures and determine eligibility. Parental consent and child assent (for children seven years of age and older) were 
TABLE 1

Reasons for specific room preference and factors considered important to procedure location

\begin{tabular}{|c|c|}
\hline Category & Definition \\
\hline Convenience & Easier or more convenient \\
\hline Comfort & $\begin{array}{l}\text { More comfortable physically or } \\
\text { emotionally for the child }\end{array}$ \\
\hline Medical/physical condition & $\begin{array}{l}\text { Child's medical or physical condition is } \\
\text { unstable or limits mobility }\end{array}$ \\
\hline Procedure type & $\begin{array}{l}\text { The invasiveness or length of the } \\
\text { procedure }\end{array}$ \\
\hline Ability to cope & Child's ability to cope with procedures \\
\hline Age & Child's chronological age \\
\hline $\begin{array}{l}\text { Cognitive-developmental } \\
\text { status }\end{array}$ & $\begin{array}{l}\text { Child's level of awareness of } \\
\text { surroundings and understanding of } \\
\text { medical procedures }\end{array}$ \\
\hline Family support & Parent and/or family can provide support \\
\hline Fear & $\begin{array}{l}\text { Concern that the child will develop fear } \\
\text { or anxiety associated with the room } \\
\text { in which the procedure is performed }\end{array}$ \\
\hline Equipment & $\begin{array}{l}\text { The room is better equipped for safety or } \\
\text { comfort of the child }\end{array}$ \\
\hline Privacy & $\begin{array}{l}\text { Concern for the privacy of the child or } \\
\text { others }\end{array}$ \\
\hline Sterility & Sterile conditions could be provided \\
\hline $\begin{array}{l}\text { Parent and/or child } \\
\text { preference }\end{array}$ & $\begin{array}{l}\text { Parent and/or child should be asked for } \\
\text { their opinion }\end{array}$ \\
\hline No need to move & $\begin{array}{l}\text { Not necessary to move the child or } \\
\text { detrimental to move the child }\end{array}$ \\
\hline Room not important & $\begin{array}{l}\text { The room did not make a difference or } \\
\text { the issue is not important }\end{array}$ \\
\hline $\begin{array}{l}\text { Health care provider } \\
\text { decision }\end{array}$ & $\begin{array}{l}\text { Decision should be left up to the doctors } \\
\text { or nurses }\end{array}$ \\
\hline Unable to score & $\begin{array}{l}\text { Reason provided cannot be scored into } \\
\text { the established categories }\end{array}$ \\
\hline
\end{tabular}

Scoring categories were applicable to both rooms for questions regarding room preference

obtained. Only two parents declined participation, stating that they felt too overwhelmed by their child's hospitalization. In most situations, parents were interviewed in the hospital room in the presence of their children. Because it was likely that some parents and children may not have had experience with a treatment room, the researcher provided detailed, standardized information to all parents and children about this room before beginning the interview. Specifically, the researcher explained that procedures could be performed in the treatment room and that one was available on the same floor as their child's hospital room. The setup of the treatment room was also described (eg, procedure table, supplies, equipment), and parents were informed that they were allowed to accompany their children and remain with them in the treatment room. Specific clinical issues, such as the development of fear associated with the child's hospital room, were not discussed with the parents. The interview lasted between 10 and $30 \mathrm{~min}$, depending on the amount of detail provided. Any additional comments provided by parents were recorded.

\section{Measures}

The following data were gathered via interview, with the exception of the demographic data that could be recorded from hospital records. The measures described below are presented in the same order as they were obtained in the interview.

Demographics: The child's age, sex and inpatient ward were recorded. Parents were asked to provide the reason for their children's admission, information about any chronic medical condition and the number of previous hospitalizations since the child was one year of age. In addition, parents were asked about the presence and severity of physical and/or cognitive impairments in their children.

Parent preference for procedure site: Parents were asked about the number of previous experiences with specific procedures and the previous site of performance (hospital room or treatment room). The procedures presented (selected because they were common procedures performed on an inpatient basis) were blood test, intravenous line placement, bladder catheterization, bandage change, drain removal, chest tube removal, lumbar puncture (LP), bone marrow aspiration (BMA) and peripheral intravenous catheter line. Procedures experienced in the operating room under general anesthesia (eg, bladder catheterizations, intravenous insertions), in the emergency room, in an outpatient clinic or at home (eg, infusaport cleaning) were not counted as previous inpatient procedure experience or included in the total number for that specific procedure. If parents and children had experience with both rooms, they were asked to indicate with which room they had the most experience. For those procedures previously experienced, parents were asked for their preferred procedure site (hospital room or treatment room) and to explain their choice. Parents were not asked to explain the reason for room selection for each procedure individually but rather to explain for the group of procedures preferred in one room or the other (eg, they might be asked why they preferred the hospital room for a blood test, intravenous insertion and bandage change).

General considerations for procedure site: Parents were asked to describe the factors that they believed medical personnel should consider when deciding between a treatment room or a hospital room for an inpatient procedure. Parents were asked to answer with respect to a general pediatric population, not in response to their own child.

Level of importance of specific factors: Parents were asked to rate how important the following factors were to the procedure site decision: age of the child (younger versus older); type of procedure (more invasive and/or serious versus less invasive and/or serious); child's ability to cope with procedures (copes well versus copes poorly); medical or physical condition (feeling poorly versus feeling relatively well); and type of hospital room (private versus semiprivate). These factors were selected for evaluation because they were the most frequently mentioned in the nursing study described previously (15). Parents rated level of importance for these factors on the following descriptive scale: 'not at all important', 'a little important', 'somewhat important', 'very important' or 
'extremely important'. If parents rated the factor as having any level of importance, they were then asked in what way that factor should influence room choice. For example, parents were asked which room would be more appropriate for the younger child and which room for the older child.

Child preference for procedure site: Children five years of age and older without cognitive delay were asked which room they would prefer for medical procedures. Children were asked to give their preference for procedures in general rather than for individual procedures. Before asking the question, the researcher reviewed with the children the concept of the treatment room in the same standardized manner as with the parents. Children who responded to the question were asked to explain why they selected a particular room.

\section{Scoring of open-ended interview questions}

To score the open-ended questions, approximately $20 \%$ of the interviews were reviewed to identify nonoverlapping categories (Table 1). Following the development of the scoring categories, two researchers independently scored the open-ended questions for each interview, and interrater reliability was established using percentage agreement. Scoring discrepancies were resolved by discussion between the researchers.

\section{RESULTS}

\section{Overview of analyses}

Descriptive statistics (frequencies) are used to summarize and present the data. Analyses were planned to evaluate the effects of age, previous experience, coping ability and medical condition on location preference; however, the small number of parents who preferred the treatment room for specific procedures precluded the majority of these analyses. The blood test and intravenous insertion were the procedures that had the greatest numbers of parents preferring the treatment room. Therefore, ${ }^{2}$ analyses were performed on preferred location (hospital room or treatment room) for these procedures. Age group, coping ability, medical condition (yes/no) and previous experience (grouped by the number [none, low, moderate and high] of previous blood tests, intravenous insertions and number of previous hospital admissions) were examined in these ${ }^{2}$ analyses. None of these analyses was significant; therefore, they are not mentioned in the following results. The data were also examined to determine whether meaningful patterns of responses could be discerned between other variables.

\section{Demographics}

The majority of children (45\%) were admitted for medical treatment related to an acute or chronic medical condition (eg, intravenous antibiotic treatment for an infection or chemotherapy for leukemia). Twenty-five per cent of the children were hospitalized for surgery, $19 \%$ for evaluation of new symptoms following a previously diagnosed disorder and $12 \%$ for an initial diagnostic workup of symptoms. Eighty-one per cent of the children had a chronic medical condition (although this was not always the reason for the
TABLE 2

Previous experience and parent's procedure site preference

\begin{tabular}{|c|c|c|c|c|c|}
\hline \multirow[b]{2}{*}{ Procedure } & \multirow[b]{2}{*}{ n (\%) } & \multicolumn{2}{|c|}{$\begin{array}{l}\text { Previous } \\
\text { experience }\end{array}$} & \multicolumn{2}{|c|}{ Site preference } \\
\hline & & $\begin{array}{c}\text { HR } \\
\text { n (\%) }\end{array}$ & $\begin{array}{c}\text { TR } \\
\mathrm{n}(\%)\end{array}$ & $\begin{array}{c}\text { HR } \\
\text { n (\%) }\end{array}$ & $\begin{array}{c}\text { TR } \\
\text { n (\%) }\end{array}$ \\
\hline Blood test & 134 & $\begin{array}{l}133 \\
(99)\end{array}$ & $\begin{array}{c}1 \\
(1)\end{array}$ & $\begin{array}{l}119 \\
(89)\end{array}$ & $\begin{array}{l}15 \\
(11)\end{array}$ \\
\hline Intravenous insertion & 123 & $\begin{array}{l}120 \\
(98)\end{array}$ & $\begin{array}{l}3 \\
(2)\end{array}$ & $\begin{array}{l}103 \\
(84)\end{array}$ & $\begin{array}{l}20 \\
(16)\end{array}$ \\
\hline Bandage change & 61 & $\begin{array}{c}61 \\
(100)\end{array}$ & 0 & $\begin{array}{c}53 \\
(88)\end{array}$ & $\begin{array}{c}8 \\
(12)\end{array}$ \\
\hline $\begin{array}{l}\text { Bladder } \\
\quad \text { catheterization }\end{array}$ & 38 & $\begin{array}{l}37 \\
(97)\end{array}$ & $\begin{array}{c}1 \\
(3)\end{array}$ & $\begin{array}{l}29 \\
(76)\end{array}$ & $\begin{array}{c}9 \\
(24)\end{array}$ \\
\hline Drain removal & 32 & $\begin{array}{c}32 \\
(100)\end{array}$ & 0 & $\begin{array}{c}27 \\
(84)\end{array}$ & $\begin{array}{c}5 \\
(16)\end{array}$ \\
\hline Chest tube removal & 15 & $\begin{array}{c}15 \\
(100)\end{array}$ & 0 & $\begin{array}{c}15 \\
(100)\end{array}$ & 0 \\
\hline Lumbar puncture & 24 & $\begin{array}{c}8 \\
(33)\end{array}$ & $\begin{array}{l}16 \\
(67)\end{array}$ & $\begin{array}{c}8 \\
(33)\end{array}$ & $\begin{array}{l}16 \\
(67)\end{array}$ \\
\hline $\begin{array}{c}\text { Bone marrow } \\
\text { aspiration }\end{array}$ & 16 & $\begin{array}{c}1 \\
(6)\end{array}$ & $\begin{array}{l}15 \\
(94)\end{array}$ & $\begin{array}{c}1 \\
(6)\end{array}$ & $\begin{array}{l}15 \\
(94)\end{array}$ \\
\hline $\begin{array}{l}\text { Peripheral } \\
\text { intravenous } \\
\text { catheter }\end{array}$ & 5 & $\begin{array}{c}5 \\
(100)\end{array}$ & 0 & $\begin{array}{c}2 \\
(40)\end{array}$ & $\begin{array}{c}3 \\
(60)\end{array}$ \\
\hline
\end{tabular}

HR Hospital room; TR Treatment room

current admission). The majority of the children with a chronic diagnosis had either a neurological condition (32\%), or a blood disease or cancer (26\%). Eighteen per cent of the children had mild to profound developmental delay or cognitive impairment according to the parent's report. Seventeen children had mild (eg, tremor) to severe (eg, quadriplegia or inability to ambulate) motor impairment. Fifteen per cent of the children had mild to severe (cortical blindness) vision loss, and $4 \%$ had mild or moderate hearing loss.

\section{Procedure site experience and preference}

The majority of children experienced their previous medical procedures in a hospital room, with the exception of children with cancer, whose LPs and BMAs were more likely to be performed in the treatment room (Table 2). The hospital room was selected by the majority of parents as the preferred site for what might be considered 'minor' medical procedures, for example, a blood test, intravenous insertion and bandage change. Parents also selected the hospital room for chest tube removals, which might be considered an invasive or painful procedure but is shorter in duration than other invasive procedures. What is not apparent in the table is that 23 parents $(14 \%)$ preferred the treatment room as the procedure site (for a variety of procedures) despite previous experience in the hospital room. The only parents to prefer the hospital room when their previous experience was with the treatment room were the parents of five children with cancer (undergoing BMAs and LPs).

Seventy-one per cent of the 106 children who were eligible (ie, who were at least five years of age and without cognitive impairment) answered the question regarding procedure 
TABLE 3

Parent and child reasons for procedure site preference

\begin{tabular}{lcccc}
\hline & \multicolumn{2}{c}{ Parent } & \multicolumn{2}{c}{ Child } \\
Category & HR, & TR & HR & TR \\
Convenience & $26(19)$ & $3(7)$ & $6(11)$ & 0 \\
Comfort & $34(25)$ & $4(9)$ & $9(16)$ & $4(19)$ \\
Medical/physical & $17(12)$ & 0 & 0 & 0 \\
$\quad$ condition & & & & \\
Procedure type & $11(8)$ & $10(23)$ & $10(18)$ & $5(24)$ \\
Ability to cope & $9(6)$ & $3(7)$ & $3(5)$ & 0 \\
Child's age & $3(2)$ & $2(5)$ & 0 & 0 \\
Family support & $6(4)$ & 0 & $2(4)$ & 0 \\
Fear & $10(7)$ & $9(20)$ & 0 & 0 \\
Equipment & $1(1)$ & $14(32)$ & 0 & 0 \\
Privacy & $4(3)$ & $11(25)$ & $1(2)$ & $8(38)$ \\
Sterility & $1(1)$ & $3(7)$ & 0 & 0 \\
Developmental status & $1(1)$ & $1(1)$ & 0 & 0 \\
No need to move & $13(9)$ & 0 & 0 & 0 \\
Do not know & $9(7)$ & 0 & $25(45)$ & $4(19)$ \\
Room not important & $6(15)$ & 0 & 0 & 0 \\
Nurse's or doctor's & $2(1)$ & 0 & 0 & 0 \\
$\quad$ decision & $10(7)$ & $1(2)$ & $3(5)$ & 0 \\
Unable to score & 139 & 43 & 56 & 21 \\
Total & & & &
\end{tabular}

HR Hospital room; TR Treatment room

site. Data from $29 \%$ of the 106 eligible children were missing due to the child being ill (eg, nauseated), in pain, sedated from medication, out of the room (eg, in the hospital playroom or classroom) or unresponsive due to apparent shyness. The majority $(65 \%)$ of children answering the question reported a preference for procedures to be done in the hospital room. The treatment room was selected by $17 \%$ of the children, and $11 \%$ of the children spontaneously indicated that they would prefer both rooms. Seven per cent of the children stated that they did not know which room they would prefer. Some children disagreed with their parent's stated room preference. For example, eight children selected the treatment room for procedures in general when their parents selected the hospital room for each procedure experienced.

Reasons for procedure site preference: The reasons for the parents' and children's selections of a particular room are presented in Table 3. Agreement for category scoring was $97 \%$ for the parent responses and $99 \%$ for the child responses.

Parent reasons: The most frequently stated reasons for parents' selection of the hospital room as the preferred procedure site were comfort (eg, "because he's more at ease and secure here", "some think that the bed should be the child's haven, but not for us, procedures done here are fine for him"), convenience (eg, "it's just easier") and medical condition (eg, "if he is feeling bad, it is really hard on him to get in a wheelchair and be hauled to the treatment room"). Although mentioned by a smaller proportion of parents, the issue of creating fear in children by removing them from the hospital room was raised (eg, "I think it would traumatize her to go to a treatment room because it would make her think that it was worse than it was going to be"). There were some parents who simply stated that it was either detrimental or not necessary to move their child to a treatment room, but did not provide further clarification. Some parents who selected the hospital room stated that the issue was not important or that the room did not make a difference (eg, "being in a hospital is being in a hospital, changing rooms is not going to cut down on his fear"). Finally, some parents stated that the decision should be left to health care staff (eg, "whatever they think is best for him").

Parents' preferences for the treatment room were explained primarily by the need for and availability of special equipment or supplies (such as monitoring equipment for conscious sedation or diversionary materials such as music), privacy for the child or roommate and the type of procedure. The desire to avoid fear associated with the hospital room was raised by a number of families who had comments similar to those of the parent who stated that "children need to associate their hospital room with a safe place and not panic when people enter."

Child reasons: Almost half of the children who selected the hospital room as their preferred site for procedures were unable to explain their preference. The children who could verbalize their reasons most frequently preferred the hospital room because of the type of procedures that they had experienced (described as minor or not painful), because they were more comfortable in their room or because it was more convenient to have procedures in their room. The children's reasons for selecting the treatment room most frequently concerned privacy and personal comfort. Several children with privacy concerns indicated that they were worried about others hearing them cry if they had difficulty coping with the procedure (eg, "I would rather be in another room in case it hurts and I have to scream").

\section{General considerations for deciding on the procedure site}

Table 4 presents the factors described by parents as being important considerations when deciding where to perform procedures. Percentage agreement for scoring the categories was $98 \%$. Some of the parents' responses were general, providing an issue without mentioning the specific room. Other responses were more specific, justifying one room over the other for a particular reason. The type of procedure and the need for privacy (for both the patient and the roommate) were most frequently raised by parents as important considerations for procedure site. Only a few parents mentioned the issue of the child associating fear with the room (hospital room or treatment room) in which the procedure was performed.

\section{Level of importance of other factors}

The level of importance ratings given by parents to the factors presented by the researcher are presented in Table 5. For simplicity, the five categories of level of importance were combined into three groups - not at all, a little/somewhat and 
TABLE 4

Parent report of factors to be considered for procedure site selection

Category n (\%)

Convenience

$9(7)$

Comfort

Medical/physical condition

Procedure type

Ability to cope

Child's age

Family support

Fear

Equipment

Privacy

Sterility

Parent/child preference

Developmental status

Room not important

$1(<1)$

Doctors'/nurses' decision

$1(<1)$

\section{Examples}

"Convenience for child and medical personnel"

"Where would be the easiest and most convenient to patient"

"No need to move, too much trouble"

"Where the child will be most comfortable"

"Should consider the comfort of the patient"

"Consideration for the child's feelings"

"Depends on the pain he's feeling"

"Child's stability; how sick they're feeling"

"Physical condition at time - sluggish or not"

" tubes make it difficult to move him"

"Has severe incisions from surgery that could be affected by repositioning and moving"

"Depends on treatment involvement; time, duration of procedure"

"Degree of pain - If it is going to be very painful it is best to take them to a treatment room"

"Blood stick, IV fine in room, anything else in separate room"

"How in depth procedure will be so if possibility of adverse reactions then a quick access to OR if in trouble"

"Seriousness of procedure"

"Depends on how they cope"

"Medical personnel should consider the individual child and how they handle things"

"Depends on the child and their maturity level"

"Younger children because of age do better in a treatment room; older children, more comfortable in hospital room - they are used to having procedures"

"Make sure the parent is present"

"Depends on parent's involvement"

"Parents need to be present"

"Family - it's important just to be with them"

"Younger children associate pain with each person that walks in the room if they have procedures done in the hospital room. They should be taken to a treatment room" "Scary to move them"

"More equipped"

"Everything being at hand"

"Can be traumatizing to roommate if done in hospital room"

"Modesty is an issue with her now"

"Treatment room for privacy, treatment room also would be good because other children would not be scared"

"As long as it is private, things can be done in the hospital room"

"They should take into consideration whether the child is in a private or semiprivate room. If [name] hears something going on in the next bed he gets really scared also. Also, if they are doing something to him it may scare the other child"

"They should think about how clean the room is for more serious things"

"Susceptible to getting sick - treatment room is more sterile"

"Cleanliness of room is important in decision - treatment room is more sterile"

"Ask the kids where they want to be if old enough, otherwise ask the parents"

"Consider desires of patients and parents"

"Developmental delay - do kids understand? scary to move them"

"Stay in room if developmentally delayed"

"Room doesn't matter much"

"Room doesn't make a difference"

"Leave it up to doctors and nurses"

"Doctors' opinions matter" 
TABLE 5

Parent's level of importance ratings for procedure site decision

\begin{tabular}{lccc}
\hline & $\begin{array}{c}\text { Not at all } \\
\text { important } \\
\mathbf{n}(\%)\end{array}$ & $\begin{array}{c}\text { A little/somewhat } \\
\text { important } \\
\mathbf{n}(\%)\end{array}$ & $\begin{array}{c}\text { Very/extremely } \\
\text { important } \\
\mathbf{n}(\%)\end{array}$ \\
\hline Age of child & $27(17)$ & $34(22)$ & $95(61)$ \\
Procedure type & $9(6)$ & $23(14)$ & $127(80)$ \\
$\begin{array}{l}\text { Child's coping } \\
\text { ability }\end{array}$ & $18(11)$ & $23(15)$ & $116(74)$ \\
$\begin{array}{c}\text { Medical } \\
\text { condition }\end{array}$ & $12(8)$ & $25(16)$ & $119(76)$ \\
$\begin{array}{c}\text { Type of hospital } \\
\text { room }\end{array}$ & $12(8)$ & $19(12)$ & $127(80)$ \\
\hline
\end{tabular}

very/extremely. As can be seen, the majority of ratings fell within the very/extremely important range for all the factors. However, there were a considerable number of parents who felt that these factors were not at all important. Parents' reports of how each factor influenced room choice were divided into three content categories, in addition to categories for 'do not know' responses and responses that were unable to be scored (Table 6). The majority of parents indicated that more invasive procedures should be done in the treatment room and that a semiprivate room dictated the use of a procedure room. There were relatively equal numbers of parents stating that the treatment room and hospital room were appropriate for both the younger and older child. There were also a considerable number of parents who, despite ranking the factor as important, could not clearly describe how the factor impacted room choice.

\section{DISCUSSION}

This descriptive study, while preliminary in nature, raises questions concerning the practical application of a blanket recommendation to perform inpatient procedures outside the child's hospital room. The majority of parents and children preferred the hospital room for inpatient procedures, with the exception of oncology procedures (LPs and BMAs), which were preferred in the treatment room. Although there were no definitive influences of age, medical condition, or extent of

TABLE 6

Parent ratings of the influence of specific factors on procedure location

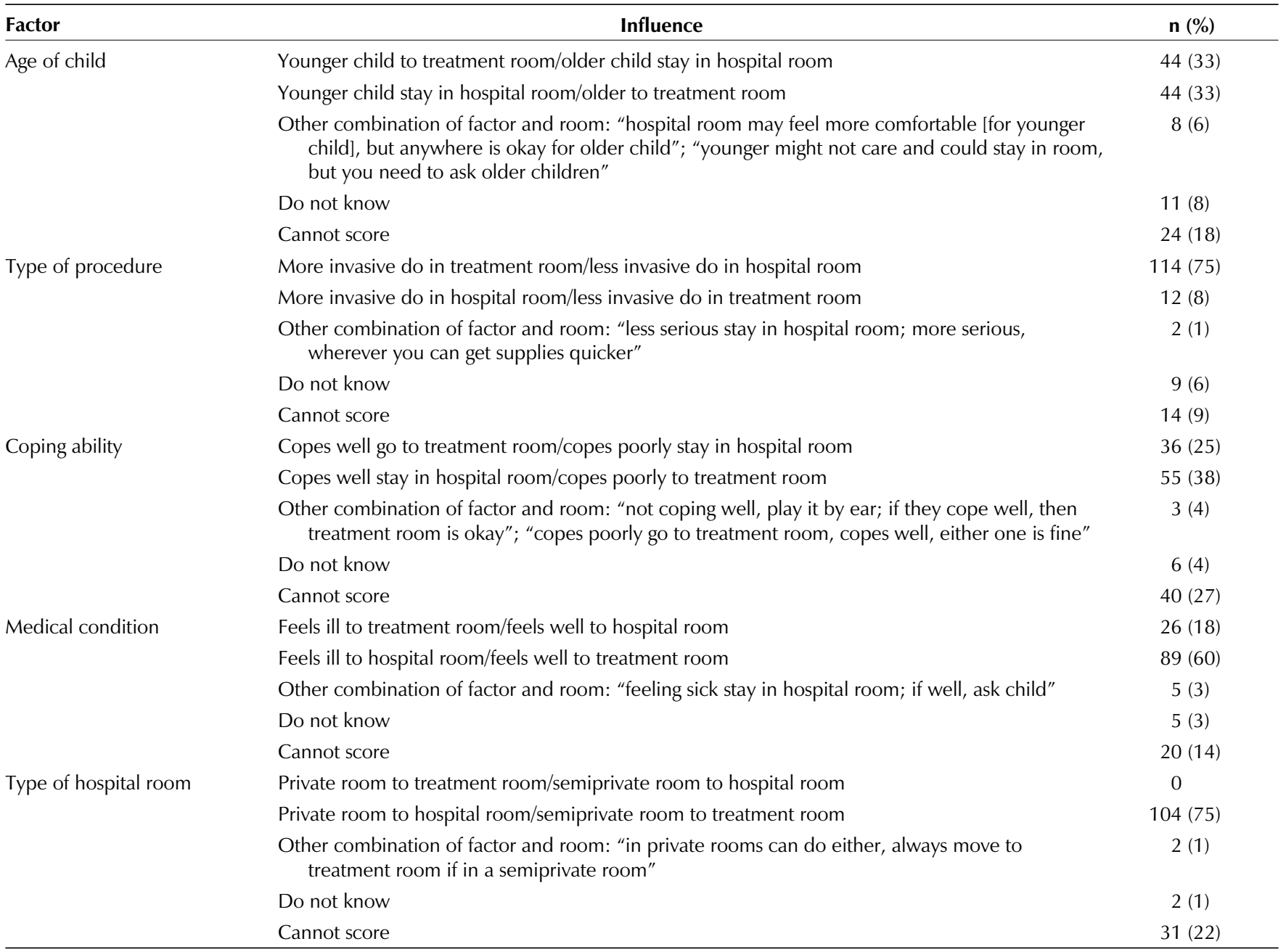


previous procedure or hospital experience on procedure site preference, the majority of these analyses were hampered by the small number of parents preferring the treatment room for various tests.

Many parents shared previous experiences with medical procedures that provided interesting anecdotal data. Although some of the parents described positive past experiences with treatment rooms, there were a number of negative experiences recounted. For example, one parent recalled that children in another hospital referred to the treatment room as the 'torture room' and wanted to stay in their own hospital room for medical procedures. Some parents stated that they were not allowed to accompany their child to their treatment room. Other parents explained that moving the child to a treatment room was not helpful because of the child's difficulty in coping, regardless of the procedure site. The practical issue of using a treatment room was raised by one parent who asked, "Would it be possible to do every procedure in a treatment room? People would be lined up outside the door." A few parents indicated that factors other than procedure site were more important, such as the skill of the person performing the procedure (eg, "it would help if they would get someone who knew how to do it best") and preparation for the procedure (eg, "if nurses come in and explain what they are going to do at his level, he has a tendency to do a little better").

There are certainly a number of limitations to this preliminary study. The lack of previous experience with a treatment room made it difficult to separate out the effects of previous location experience. The justifications that parents provided for their selection of the hospital room were reasonable; however, there were a considerable number of parents who could not clearly explain why they preferred the hospital room for procedures. Therefore, even though the purpose of the treatment room was explained in some detail, we cannot be certain that the choice of the hospital room did not result simply from previous experience with only that room. Another limitation is that parents were interviewed in the presence of their children, which may not only have inhibited parents' abilities to talk freely but also influenced children's reports of their room preference.

\section{REFERENCES}

1. Fanurik D, Koh JL, Schmitz ML. Nurse-provided distraction combined with EMLA: Effects on IV insertion pain and distress in children. Child Health Care 2000;29:87-101.

2. Kazak AE, Penati B, Boyer BA, et al. A randomized controlled prospective outcome study of a psychological and pharmacological intervention protocol for procedural distress in pediatric leukemia. J Pediatr Psychol 1996;21:615-31.

3. Cohen LL, Blount RL, Panopoulos G. Nurse coaching and cartoon distraction: An effective and practical intervention to reduce child, parent, and nurse distress during immunizations. J Pediatr Psychol 1997;22:355-70.

4. Vessey JA, Carlson KL, McGill J. Use of distraction with children during an acute pain experience. Nurs Res 1994;43:369-72.

5. Fowler-Kerry S, Lander JR. Management of injection pain in children. Pain 1987;30:169-75.

6. French GM, Painter EC, Coury DL. Blowing away shot pain:
The findings of this study, combined with our clinical experience, suggest that there may be too many confounding issues surrounding the performance of inpatient procedures for parents to easily weigh the advantages and disadvantages of the treatment room or hospital room. For example, the clinical approach to inpatient procedures is often not consistent. There can be considerable variability across settings concerning whether parents are allowed in the treatment room, as well as the condition and availability of the treatment room. Some treatment rooms are more convenient to hospital rooms than others and are better equipped, not only with supplies and space, but also with diversionary materials. Finally, the technical skill of the personnel conducting procedures, as well as the implementation of pharmacological or behavioural interventions, is also variable.

Our findings, at minimum, suggest a diversity of opinions and practical considerations regarding inpatient procedures that have yet to be considered in the pediatric pain literature. Future research in this area is needed to help provide better guidelines. For example, studies that assess parent and child preferences when they have experienced both the hospital room and treatment room are needed. Controlled studies of outcomes when procedures are experienced in both rooms would be one way to compare the benefits of either site for specific children. Until such data are obtained, it seems worthwhile to educate parents of hospitalized children on the issues surrounding the advantages and disadvantages of performing procedures in either room, and to obtain their input. If parents and children have no preference for the procedure site, health care personnel might consider factors such as the type of procedure, the ability to move the child (medical stability or potential to cause discomfort), the child's coping ability, the availability of supplies and equipment, and the presence of a roommate or visitors. Regardless of the site of the procedure, pharmacological intervention, and behavioural preparation and/or intervention should be implemented.

ACKNOWLEDGMENTS: The authors thank Deric Patterson for his assistance in data collection.
A technique for pain management during immunization. Pediatrics 1994;93:384-8.

7. Department of Health and Human Services. Acute pain management in infants, children, and adolescents: Operative and medical procedures (ACHCPR Publication No. 92-0020). Silver Spring: AHCPR Publications Clearinghouse, 1992.

8. Ball J, Bindler R. Pediatric Nursing: Caring for Children, 2nd edn. Stamford: Appleton \& Lange, 1999:197.

9. McCaffery M, Beebe A. Pain: Clinical Manual for Nursing Practice. St Louis: The CV Mosby Company, 1989:264-306.

10. Speer KM. Pediatric nursing. In: Pixler SL, Schmidt CK, eds. NSNA Review Series. Albany: Delmar Publishers Inc, 1994:80.

11. Wong DL. Reaction of the child and family to illness and hospitalization. In: Rollins JH, ed. Whaley \& Wong's Essentials of Pediatric Nursing, 4th edn. St Louis: Mosby - Year Book, Inc, 1993:582-34. 
12. Zeltzer LK, Altman A, Cohen D, LeBaron S, Munuksela EL, Schechter NL. Report of the Subcommittee on the Management of Pain Associated with Procedures in Children with Cancer. Pediatrics 1998;86:826-31.

13. Weisman SJ, Schechter NL. The management of pain in children. Pediatr Rev 1991;12:237-43.

14. Schechter NL, Blankson V, Pachter LM, Sullivan CM, Costa L. The ouchless place: no pain, children's gain. Pediatrics 1997;99:890-4.

15. Fanurik D, Schmitz M, Martin GA, et al. Hospital room or treatment room: Where should inpatient pediatric procedures be performed? Child Health Care 2000;29:103-11.

16. Bauchner H. Procedures, pain, and parents. Pediatrics 1991;87:563-5.
17. Bauchner H, Vincei R, May A. Teaching parents how to comfort their children during common medical procedures. Arch Dis Child 1994;70:548-50.

18. Blount RL, Bachanas PJ, Powers SW, et al. Training children to cope and parents to coach them during routine immunizations: Effects on child, parent, and staff behavior. Behav Ther 1992;23:689-705.

19. O’Laughlin E, Ridley-Johnson R. Maternal presence during children's routine immunizations: The effect of mother as observer in reducing distress. Child Health Care 1995;24:175-91.

20. Gonzalez JC, Routh DK, Saab PG, et al. Effects of parent presence on children's reactions to injections: Behavioral, physiological, and subjective aspects. J Pediatr Psychol 1989;14:463-72. 


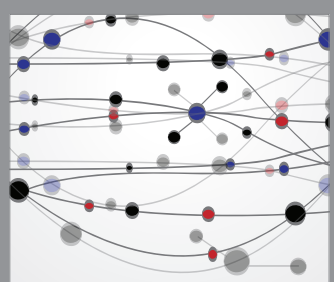

The Scientific World Journal
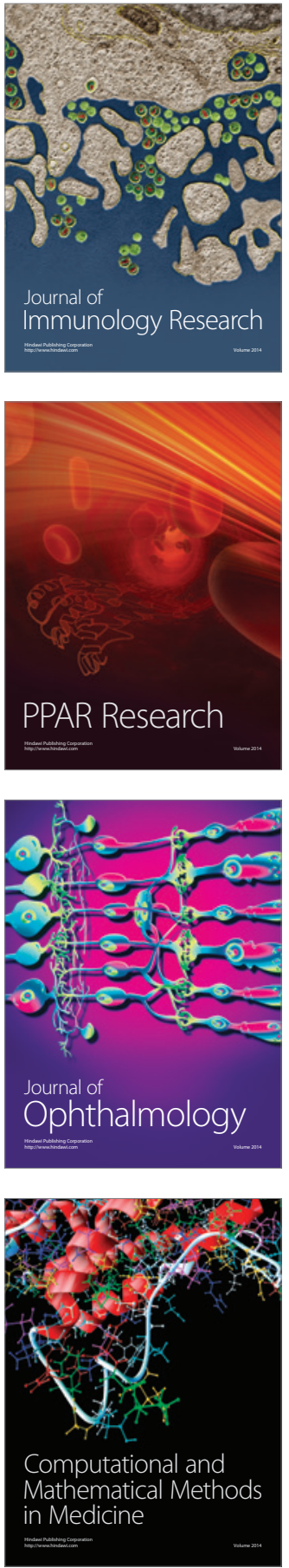

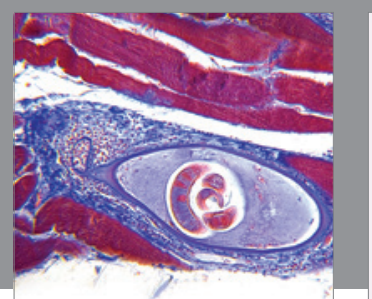

Gastroenterology Research and Practice

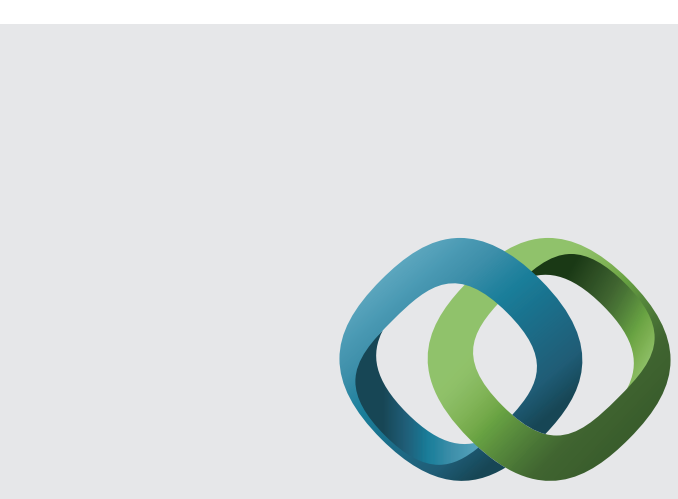

\section{Hindawi}

Submit your manuscripts at

http://www.hindawi.com
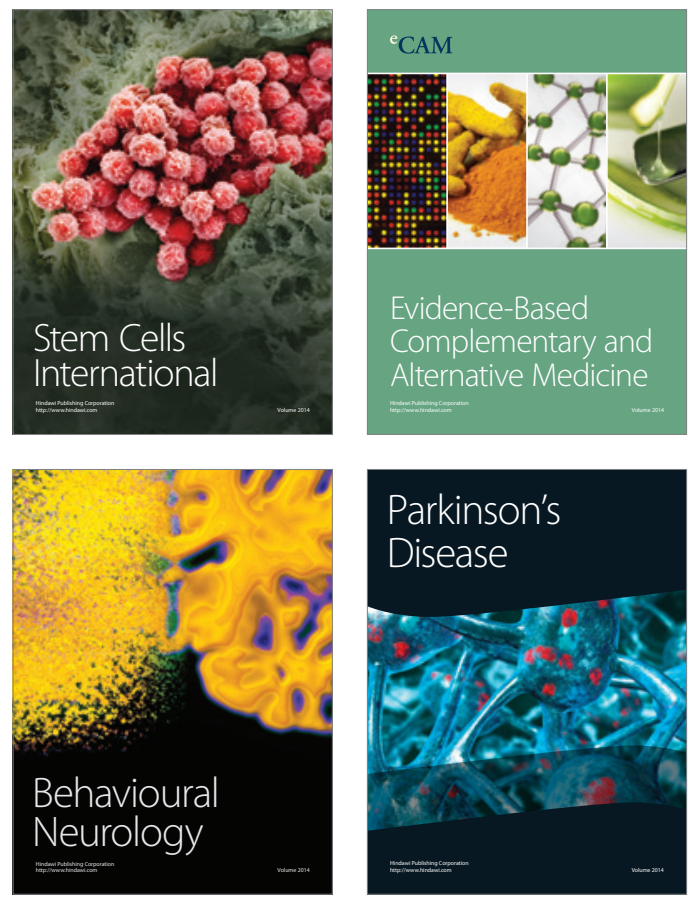
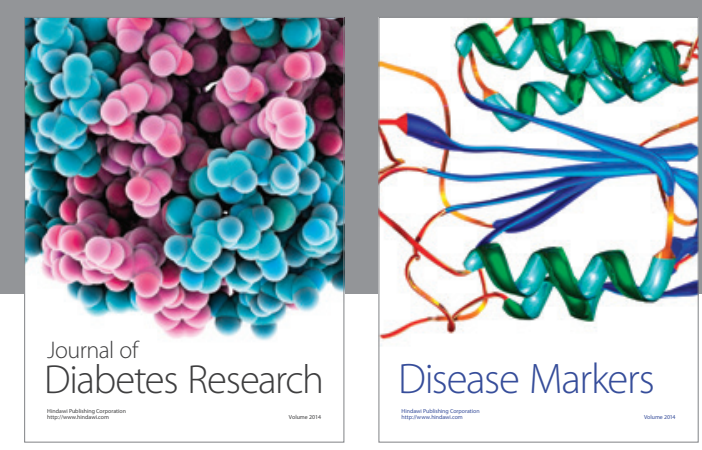

Disease Markers
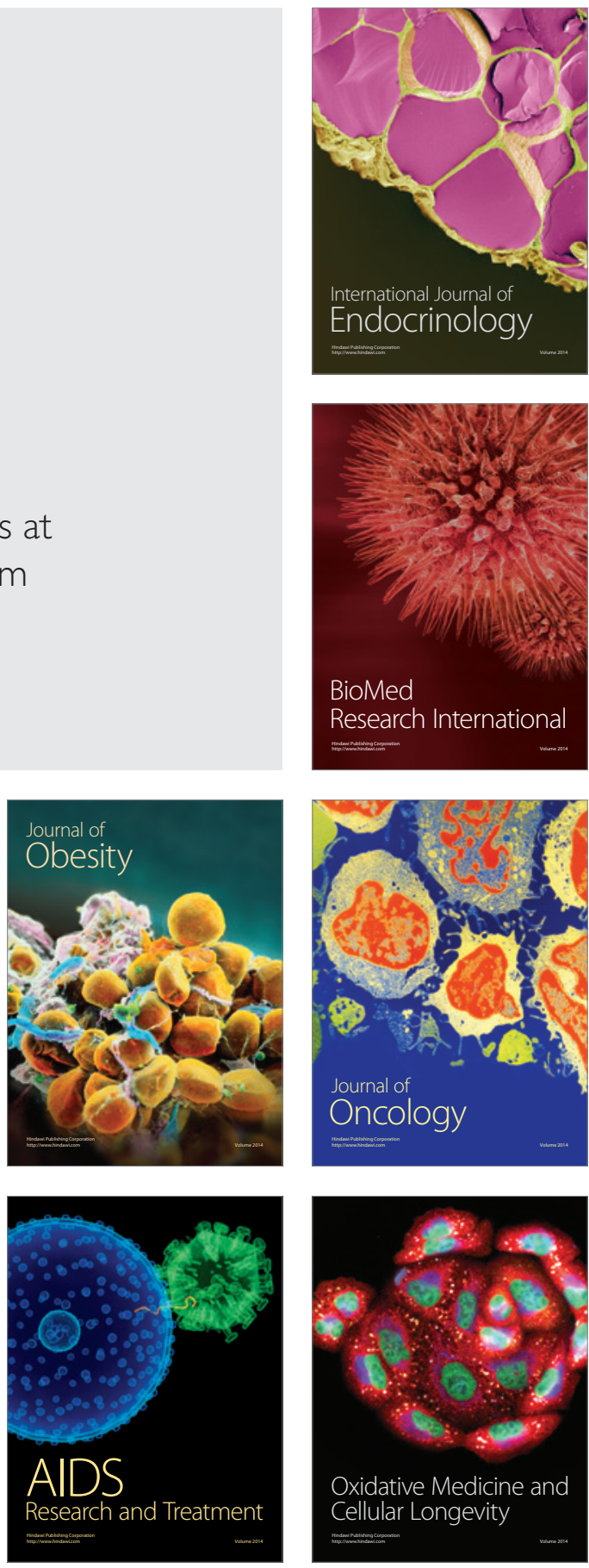